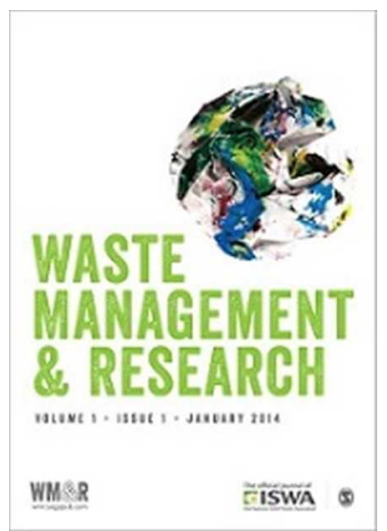

\title{
A study on the potential use of paper sludge ash in concrete with glass aggregate
}

\begin{tabular}{|c|c|}
\hline Journal: & Waste Management \& Research \\
\hline Manuscript ID & WMR-18-0104.R1 \\
\hline Manuscript Type: & Short Communications: 15,000 characters \\
\hline Date Submitted by the Author: & $\mathrm{n} / \mathrm{a}$ \\
\hline Complete List of Authors: & $\begin{array}{l}\text { Mavroulidou, Maria; London South Bank University, Civil and Building } \\
\text { Services Engineering } \\
\text { Awoliyi, Samuel; London South Bank University, Civil and Building Services } \\
\text { Engineering }\end{array}$ \\
\hline Keywords: & $\begin{array}{l}\text { Solid waste management, paper sludge ash (PSA), waste glass aggregate } \\
(\text { WGA), concrete, alkali-silica reaction (ASR) }\end{array}$ \\
\hline Abstract: & $\begin{array}{l}\text { This short communication focuses on the potential use of paper sludge ash } \\
\text { (PSA), a waste product of the paper making industry as an innovative } \\
\text { binder partially replacing cement in concrete with glass aggregate. After } \\
\text { preliminary testing using binary or ternary CEM-II mixes with PSA / } \\
\text { Pulverised Fly Ash (PFA) a suitable mix for concrete with glass aggregate } \\
\text { was identified. Concrete mixes with partial or full natural sand replacement } \\
\text { by waste glass aggregate (WGA) were then produced and showed } \\
\text { appropriate strengths and overall similar or better water absorption } \\
\text { characteristics than control mixes with natural aggregates without manifest } \\
\text { alkali-silica reaction (ASR) problems. This shows potential for applications } \\
\text { in precast dry mix concrete units based on the required strengths that } \\
\text { were achieved. }\end{array}$ \\
\hline
\end{tabular}




\section{A study on the potential use of paper sludge ash in concrete with glass aggregate}

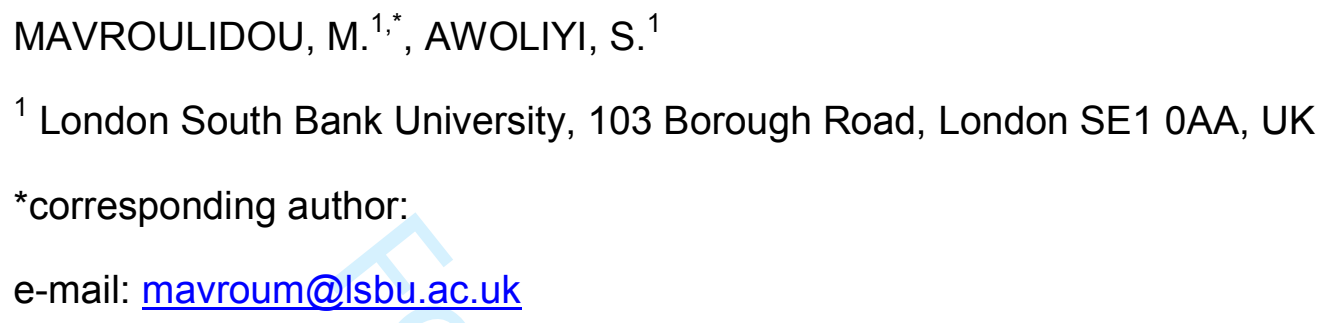

\section{A short communication submitted to Waste Management \& Research for the special issue of November 2018}

Original version submitted on the $31^{\text {st }}$ January 2018

Revised version submitted on the $12^{\text {th }}$ June 2018

Character count including spaces (main body text \& Figure/Table captions): 14995

Number of Tables: 2

Number of Figures: 2 


\begin{abstract}
This short communication focuses on the potential use of paper sludge ash (PSA), a waste product of the paper making industry as an innovative binder partially replacing cement in concrete with glass aggregate. After preliminary testing using binary or ternary CEM-II mixes with PSA/ Pulverised Fly Ash (PFA) a suitable mix for concrete with glass aggregate was identified. Concrete mixes with partial or full natural sand replacement by waste glass aggregate (WGA) were then produced and showed appropriate strengths and overall similar or better water absorption characteristics than control mixes with natural aggregates without manifest alkali-silica reaction (ASR) problems. This shows potential for applications in precast dry mix concrete units based on the required strengths that were achieved.
\end{abstract}

Keywords: Solid waste management, paper sludge ash (PSA), waste glass aggregate (WGA), concrete, alkali-silica reaction (ASR)

1. Introduction

Discarded municipal post-consumer container glass was one of the first materials to be collected and recovered as glass is chemically inert, not biodegradable and thermally stable; this allows for infinite reprocessing operations (recovery/reuse). Thus, theoretically the entire amount of recovered waste glass could be reused for new glass manufacture. Practically however, only colour-sorted and contamination-free waste glass is reusable in the glass 
industry; moreover, if distances between collection points and glass molding facilities are long reuse of post-consumer glass in the glass industry is further prevented. This leads to an increasing amount of waste glass surplus in the form of glass cullet, i.e. mixed-coloured glass fragments from the breakage of coloured glass containers (mainly from food, juice, beer and liquor bottles i.e. about $10 \%$ of the average UK household waste volume) that glass manufacturers cannot reuse: $34 \%$ of this waste glass in the UK was recently reported as non-remelt glass (Spathi, 2016). Many other countries (e.g. USA, Australia, Middle East) face similar problems (Wright et al, 2014); thus further applications are needed to create secondary recycling markets for mixed glass cullet. Glass cullet is primarily silica, as are most natural sands and gravels and closely resembles natural sand shapes if crushed down to sand size. Aggregate market therefore creates an ideal alternative to landfilling while reducing considerably the demand for new raw materials extraction and related environmental effects. Glass cullet aggregate was thus reused as a partial or full replacement of natural aggregate in concrete already in the seventies but it was soon discovered that this could lead to deleterious Alkali-Silica Reactions (ASR) between alkali oxides in the cement and the reactive silica in glass aggregate, hence structural weakness and cracks affecting concrete durability. This has caused a lack of confidence and often the banning of glass use within 
the concrete industry. However research has shown that pozzolanic materials in cement mixes e.g. Pulverised Fuel Ash (PFA), Ground Granulated Blast Furnace Slag (GGBS), Silica Fume (SF) or metakaolin (MK) can effectively counteract ASR (e.g. Almesfer \& Ingham, 2014; Shafaatian et al, 2013); some of these are industrial by-products and their use in concrete is an excellent valorisation route with the additional environmental advantage of the low or no energy demand for their production compared to Ordinary Portland Cement (OPC). There is thus a drive for additional materials from waste that can partially or fully replace cement and if used in concrete with waste glass aggregate (WGA), they can counteract or not unfavourably affect ASR. This paper studies the use of paper sludge ash (PSA) to this effect. PSA (classified as waste in the UK) is produced by the incineration of paper sludge (the main voluminous waste stream from de-inking and water treatment stages throughout the papermaking process), to reduce the volume of waste for landfilling (80-90\% reduction) and recover energy; it is subsequently disposed of in landfills in a large part. The increasing amount of PSA (in the UK 4 out 40 paper mills alone generate 140 ktonnes of PSA annually, Spathi, 2016) has caused environmental concerns and high costs to industry due to UK landfill tax (£84.40/t and £2.65/t for active and inactive waste respectively), thus the need for more sustainable alternative management options. PSA is a high calcium 

5

ash containing lime $(\mathrm{CaO})$ and reactive silica and alumina; it is therefore potentially a suitable cementitious or pozzolanic material. There is little information on the use of PSA in mortar/concrete (Ishimoto et al, 2000; Mozaffari et al, 2006 and 2009; Mavroulidou et al, 2013; Fava et al, 2011; Rajgor \& Pitroda, 2013) and further investigation is needed for the material to be used with confidence in industrial production. Furthermore, PSA used as partial cement replacement in concrete with glass aggregate has not been investigated to the authors' knowledge; this is the focus of this short communication.

\section{Materials and methods}

For this study recycled glass of $5 \mathrm{~mm}-63 \mu \mathrm{m}$ (brand name EcoSand) was obtained from Day Aggregates, a major UK aggregate supplier. According to testing performed by the suppliers, the material meets the grading requirements for precast concrete paving blocks (Day Group Ltd, 2007). This is postconsumer container waste glass, collected from London homes and commercial licensed premises (restaurants, pubs, clubs etc.) through the recycling programs of local authorities. It is processed using state of the art air-separation and washing equipment, that sorts, crushes, screens and washes glass material to produce mixed coloured (mainly green) sand-sized glass material, free of corks, caps, lids and labels. First, any loose metal is removed by an over-band 
magnet prior to primary crushing so that glass size is reduced to $24 \mathrm{~mm}$. Further loose metal released from the glass through the crushing process is then removed by a secondary magnet. The crushed glass then passes over the primary screen; the cleaned $24-6 \mathrm{~mm}$ glass is conveyed to a secondary crusher and on to a rinsing screen. All $6 \mathrm{~mm}$ glass from the primary screen and the crushed glass from the secondary crusher is washed, sized over the rinsing screen, transferred to the fines recovery plant and sent to stockpile via a dewatering screen. Glass particles larger than $6 \mathrm{~mm}$ are circulated to the secondary crusher in a closed loop; the very fine, silt-sized materials are thickened and processed into cake via a filter press and removed from the site for further processing elsewhere. Clean water is recovered from the water management plant and pumped to the rinsing screen for use in the washing process (Day Group Ltd, 2011). The plant has the capacity to wash and crush up to 55,000 t per year of mixed container glass. The coarse and fine Thames river aggregate (Fig 1) was supplied by Travis Perkins. From Fig.1 it can be seen that the glass is coarser than the natural sand used but it is within the limits for fine concrete aggregate (BSI, 1992). The specific gravity $G_{s}$ of the materials was determined as 2.65 and 2.49 for the sand and glass (WGA) respectively using $B S$ 812-2: 1995 ; the $G_{s}$ of WGA is close to the typical $G_{s}$ values for pure glass, which confirms that the tested cullet samples are free of 
debris. The cement mix materials were (a) limestone cement CEM-II/A-L:6-20\% (Lafarge-UK); (b) PFA (Cemex-450S); (c) PSA from non-hazardous free from plastic paper sludge provided by Aylesford Newsprint Ltd. (Kent, UK), produced from the sludge incineration in combined heat and power (CHP) plants at approximately $850^{\circ} \mathrm{C}$ for at least 2 seconds (EU Waste Incineration Directive, EC 2000). The PSA was not milled and was thus coarser than PFA. The PSA/PFA chemical compositions and PSD (Table 1 \& Fig. 1 respectively) are based on suppliers' data and literature using the same PSA (Spathi, 2016; Bernal et al, 2014; Mozaffari et al, 2009). PSA is a calcium aluminosilicate, as its main compounds are lime $(\mathrm{CaO})$ and silica $\left(\mathrm{SiO}_{2}\right)$ (Table 1) and has cementitious properties due to its high $\mathrm{CaO}$ content.

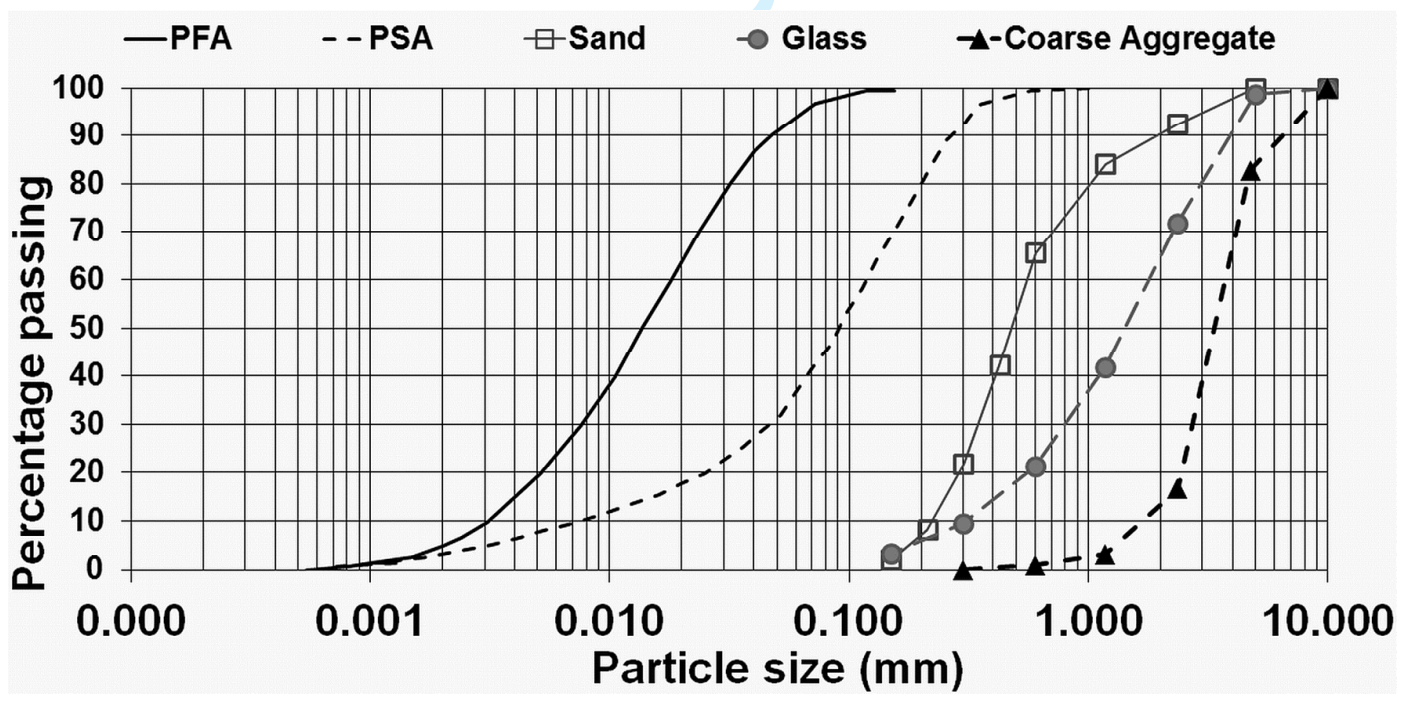

Figure 1 Particle size distribution (PSD) of aggregates and PFA/PSA binders 
Table 1 Chemical composition of cement mix components

\begin{tabular}{|l|l|l|l|}
\hline & $\begin{array}{c}\text { PFA } \\
\text { (\%) }\end{array}$ & \multicolumn{1}{|c|}{$\begin{array}{c}\text { PSA } \\
\text { (\%) }\end{array}$} & $\begin{array}{c}\text { CEM-II } \\
\text { (\%) }\end{array}$ \\
\hline $\mathrm{MgO}$ & $1-4$ & $5.15-2.72$ & 0.83 \\
\hline $\mathrm{SiO}$ & $45-51$ & $25.7-16.43$ & 18.27 \\
\hline $\mathrm{CaO}$ & $1-7$ & $61.2-43.51$ & 62.35 \\
\hline $\mathrm{Fe} \mathrm{O}_{3}$ & $7-11$ & $0.9-0.41$ & 2.21 \\
\hline $\mathrm{Al}_{2} \mathrm{O}_{3}$ & $27-32$ & $18.86-9.05$ & 4.67 \\
\hline $\mathrm{K}_{2} \mathrm{O}$ & $3-4$ & $1.31-0.22$ & 0.49 \\
\hline $\mathrm{Na}_{2} \mathrm{O}$ & 1 & $1.56-0.07$ & 0.37 \\
\hline $\mathrm{TiO}_{2}$ & 1 & $0.68-0.3$ & \\
\hline $\mathrm{SO}_{3}$ & 0.8 & $1.05-0.2$ & 2.75 \\
\hline $\mathrm{P}_{2} \mathrm{O}_{5}$ & & $0.52-0.1$ & \\
\hline $\mathrm{CaCO}_{3}$ & & & 19.63 \\
\hline $\mathrm{LOI}$ & 4.5 & 11.53 & 7.7 \\
\hline
\end{tabular}

Table 2 Concrete mix design proportions $\left(\mathrm{kg} / \mathrm{m}^{3}\right)$

\begin{tabular}{|l|l|l|l|l|l|l|l|}
\hline Mix ID & CEM-II & PFA & PSA & $\begin{array}{l}\text { Fine } \\
\text { aggregate }\end{array}$ & $\begin{array}{l}\text { Coarse } \\
\text { aggregate } \\
(\mathbf{1 0 m m})\end{array}$ & Water & $\begin{array}{l}\text { Slump } \\
(\mathbf{m m})\end{array}$ \\
\hline CEM-II & 397 & - & - & 595 & 1190 & 218 & 150 \\
\hline F20 & 317.6 & 79.4 & - & 595 & 1190 & 218 & 190 \\
\hline F20P10 & 277.9 & 79.4 & 39.7 & 595 & 1190 & 218 & 20 \\
\hline F20P15 & 258 & 79.4 & 59.6 & 595 & 1190 & 218 & 20 \\
\hline F15P10 & 297.8 & 59.6 & 39.7 & 595 & 1190 & 218 & 20 \\
\hline F15P15 & 277.9 & 59.6 & 59.6 & 595 & 1190 & 218 & 15 \\
\hline F10P10 & 317.6 & 39.7 & 39.7 & 595 & 1190 & 218 & 30 \\
\hline P10 & 357.3 & - & 39.7 & 595 & 1190 & 218 & 10 \\
\hline P15 & 337.4 & - & 59.6 & 595 & 1190 & 218 & 10 \\
\hline
\end{tabular}

Concrete was made with 1 part binder, 1.5 parts sand and 3 parts coarse aggregate (1:1.5:3) according to guidelines for RC40 (BSI, 1997); mix designs for natural aggregate mixes are shown in Table 2. For WGA concrete, the natural fine aggregate quantity $\left(\mathrm{kg} / \mathrm{m}^{3}\right)$ in Table 2 was replaced by EcoSand glass aggregate at $20 \%, 40 \%, 60 \%, 80 \%, 100 \%$ replacement levels per mass 
respectively. For consistent comparisons a constant water/binder ratio $(0.55)$ was used. Mixing was performed according to BS EN 12390-2:2009 (BSI, 2009a) using a rotating mixer. The workability of fresh mixes was assessed using the slump test (BSI, 2009b). Moulded specimens were compacted on a vibrating table; they were then water-cured at $20^{\circ} \mathrm{C}\left( \pm 2^{\circ} \mathrm{C}\right)$. Compressive strengths (100mm cubes) were determined using a Zwick Roell ToniPACT II $2000 \mathrm{kN}$ compression test plant at a loading rate of $0.6 \mathrm{MPa} / \mathrm{s}$ according to $\mathrm{BS}$ EN 12390-3:2009 (BSI, 2009c); Surface water absorption after $30 \mathrm{~min}$ immersion followed BS EN 1881-122:2011 (BSI, 2011) (scale accuracy of +/1g). Preliminary testing of a number of binary or ternary mixes of CEM-II, PSA and PFA was first performed with natural sand aggregate, to select most viable mixes for development of WGA concrete. Selection was on the basis of: a) highest CEM-II replacement levels while maintaining strengths; b) water absorption (related to concrete durability) and c) accelerated mortar bar testing results for ASR (ASTM C1260-01: ASTM, 2003) where the natural sand was fully replaced by WGA. Ternary mixes of CEM-II, PSA and PFA were used as PSA was found to lower the workability (Mavroulidou et al 2013), whereas PFA is known to increase workability (see e.g. Mavroulidou et al, 2015). PSA content was kept modest as Mavroulidou et al (2013) found a reduction in strength for 
higher PSA contents (see also 3.1). Based on this preliminary testing, a control mix was selected as the basis of WGA concrete mixes (see 3.1).

3. Results and discussion

3.1 Preliminary mixes (no glass)

Figure 2(a)-(b) shows average 7- and 28- day curing cube compressive strengths and 28-day curing water absorption respectively with standard error bars. In line with the literature (e.g. Ahmad et al, 2013; Yousuf et al 2014) all mixes with PSA regardless of PFA content were stiff to very stiff (slumps of $30 \mathrm{~mm}$ and below, see Table 2) due to the high water demand of PSA caused by its high porosity and free lime content (Wong et al 2015; Doudart de la Grée, 2012; Doudart de la Grée et al, 2018). The mixes would thus only be suitable for roller compacted/zero slump dry mix concrete e.g. for precast units (a marketed application of the CEM-II we used is precast pavement units). In line with Kadu \& Gajghate (2016) and Yousuf et al (2014) mixes with PSA only (10\% or $15 \%$ PSA) had fast early strength development and higher strengths than the control CEM-II mix due to the presence of metakaolin and portlandite (Doudart de la Grée, 2012; Doudart de la Grée et al, 2018). Conversely mixes with PFA only had lower 7 and 28-day strengths than the control CEM-II mix, commonly observed (Neville 1995; Roy et al, 2001; Mavroulidou et al 2011 and 2015). PSA positively affected strengths of PFA mixes in line with Mavroulidou 
et al (2013 and 2015) and Florea (2016). PSA did not adversely affect water absorption (in Ahmad et al 2013 or Yousuf et al, 2014 absorption slightly increased with PSA which could be due to the different characteristics of PSA used) and reduced PFA mix absorption. Considering the overall performance (strength and absorption) and maximum possible CEM-II replacement levels mix F15P15 was selected as the base cement mix for WGA concrete (labelled as 'control' mix in Fig 2(c)-(d)). ASR test of this mix showed an expansion of $0.028 \%$, well below the allowable threshold of $0.1 \%$; thus it was deemed suitable for WGA concrete. On the other hand the ability of PSA alone to counteract ASR was inconclusive as P15 expanded more than the threshold $(0.248 \%)$ whereas P10 had an acceptable expansion $(0.052 \%)$.

\subsection{Glass aggregate concrete results}

Figure 2(c)-(d) shows average 7- and 28- day curing cube compressive strengths and 28-day curing water absorption respectively with standard error bars. Most mixes with WGA showed lower strengths than the control mix; the best results were for $20 \%$ glass. Early strength gain was slower for all mixes with WGA (without however a particular pattern regarding the WGA content). The reduction in strength above 20\% WGA (due to weakened bond at the interfacial transition zone between WGA and cement paste) is in line with Ismail \& Al-Hashmi (2009) and Limbachiya (2009) and statistically significant 
$(p=0.005257$ and $p=0.0000156$ respectively from Kruskal-Wallis and one-way ANOVA tests for 28-day strengths -with 4 replications- with Bonferroni pairwise comparison $\mathrm{t}$-test showing significant differences between $0 \%, 20 \%, 80 \%$ vs $40 \%, 60 \%$ and $100 \%$ WGA).However based on strength the other mixes with higher glass content could still be used for M25 concrete (e.g. precast paving units for no traffic load). The $20 \%$ WGA concrete mix also maintained the same water absorption levels as the CEM-II mix; higher WGA levels had somewhat higher water absorptions that were not statistically significant ( $p$-value $=0.697$ and 0.838 respectively from Kruskal-Wallis and one-way ANOVA -with 3 replications-). Other properties related to compressive strength (e.g. static modulus of elasticity, $E_{c}$ ) were similarly affected as the compressive strength hence not shown here for brevity (see Mavroulidou \& Awoliyi, 2017). All WGA mixes were of low to very low slump (but not lower than the control mix); this was expected due to the slump of the control mix. If required, workability can be improved using super-plasticisers; this was beyond the scope of this study focusing on precast dry mix concrete units. For these the PSA-WGA concrete results of the studied properties are overall appropriate as they maintain values close to that of CEM-II mix with natural sand, especially for modest WGA content, and could result in material cost savings: WGA is $£ 18 /$ ton vs. $£ 50 /$ ton for natural concrete sand (according to our suppliers' prices). PSA has zero 
costs (other than transportation) as the paper sludge is anyway incinerated at the factory to reduce paper sludge waste volume. PFA and CEM-II are marketed at about $£ 0.16$ and $£ 0.24$ per kg respectively. Thus for F15P15 mix the savings in terms of cement would be about $£ 19$ per $\mathrm{m}^{3}$ of concrete and if $20 \%$ sand was also replaced by WGA about $£ 23$ per $\mathrm{m}^{3}$ of concrete $\left(£ 38\right.$ per $\mathrm{m}^{3}$ for full sand replacement).
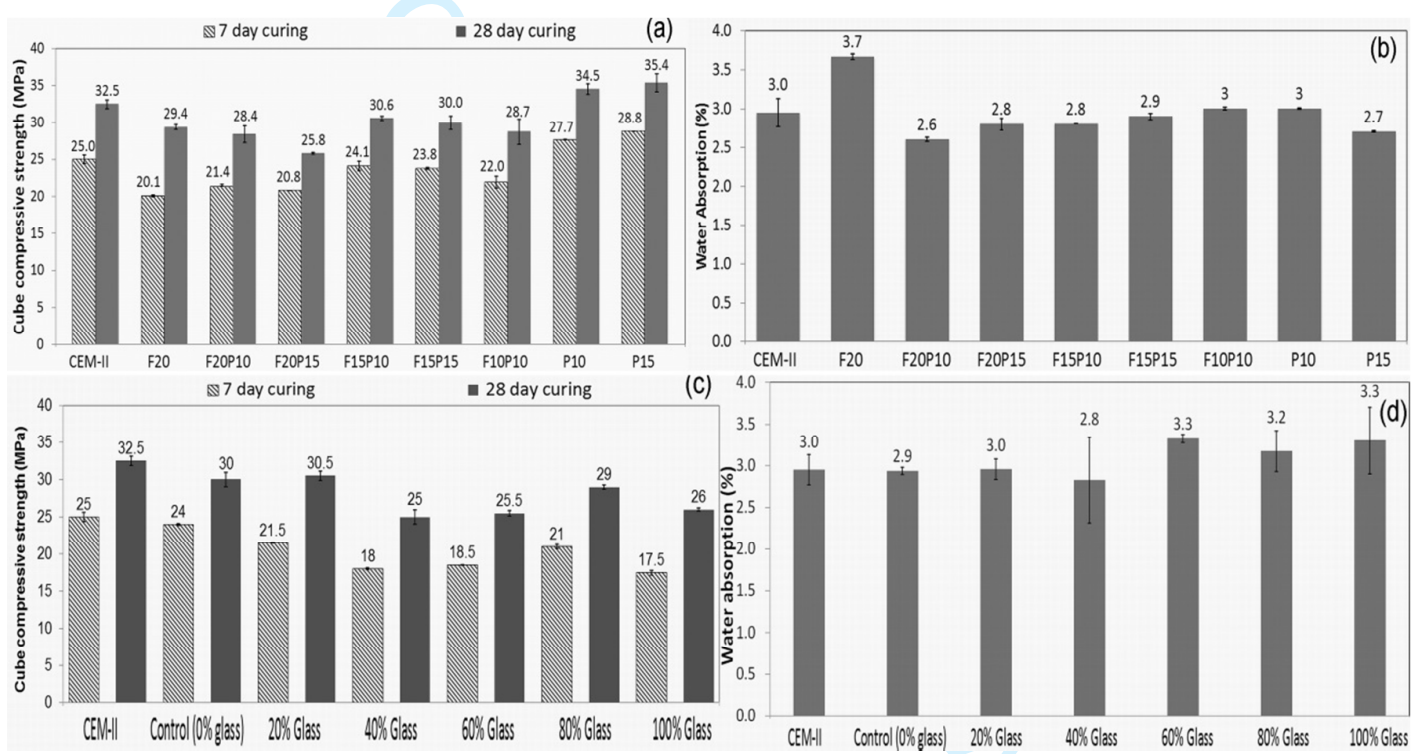

Figure 2 Hardened concrete properties: (a) Cube compressive strength of preliminary mixes; (b) Water absorption of preliminary mixes; (c) Cube compressive strength of WGA mixes; (d) Water absorption of WGA mixes

\section{Conclusions}

This paper studied the potential use of waste paper sludge ash (PSA) as a partial CEM-II replacement in WGA concrete mixes with the advantages of 
finding an additional outlet for PSA and glass cullet alternative to landfilling, while producing less energy-intensive types of concrete. The selected ternary PFA/PSA/CEM-II WGA concrete mix maintained acceptable strengths and durability performance (water absorption and ASR) for glass replacements of low levels. Further mix optimisation can address the reduced workability and potentially allow for higher glass or cement replacement levels; additional mechanical property and durability testing supported by micro-structural and chemical analysis can further assess the suitability of the suggested concrete mixes.

Acknowledgements

The study was conducted at the Concrete and Materials Laboratory of London South Bank University (LSBU), using resources fully provided by LSBU. The authors gratefully acknowledge Ms. Catherine Unsworth's assistance in carrying out the experimental programme.

References

Ahmad S, Iqbal Malik M, Bashir Wani M \& Ahmad R (2013) Study of concrete involving use of waste paper sludge ash as partial replacement of cement. IOSR Journal of Engineering 3(11): 6-15

Almesfer N \& Ingham J (2014) Effect of waste glass on the properties of concrete. Journal of Materials in Civil Engineering 26(11) : 06014022. 
American Society of Testing and Materials (ASTM) (2003) Standard test method for potential alkali reactivity of aggregates (Mortar-Bar Method). ASTM C1260-01, Annual Book of ASTM Standards, vol. 04.02.2003. ASTM, West Conshohocken

Bernal S, Ball R, Hussein O, Heath A \& Provis J (2014) Paper sludge ash as a precursor for production of alkali-activated materials. $2^{\text {nd }}$ International Conference on Advances in Chemically Activated Materials, June 1-3 2014, Changsha, China

British Standards Institution (BSI) (1992), BS 882:1992: Specification for aggregates from natural sources for concrete. BSI, London.

British Standards Institution (BSI) BS 812-2:1995: Testing aggregates Part 2. Methods of determination of density. BSI, London (1995)

British Standards Institution (BSI) (1997), BS 5328:1997. Concrete. Part 1 Guide to Specifying Concrete. BSI, London

British Standards Institution (BSI) (2009a), BS EN 12390-2: 2009. Testing hardened concrete, Part 2: Making and curing specimens for strength tests. British Standards Institution, London.

British Standards Institution (BSI) (2009b) BS EN 12350-2:2009: Testing fresh concrete. Part 2: Slump test, BSI, London. 
British Standards Institution (BSI) (2009c) BS EN 12390-3:2009: Testing hardened concrete -Part 3: Compressive strength of test specimens, BSI, London.

British Standards Institution (BSI) (2011) BS EN 1881-122:2011: Testing concrete Part 122: Method for determination of water absorption. BSI, London Day Group Ltd (2007), EcoSand, Washed Glass Sand, Paving Sand BS 7533:3 2005, from: http://www.daygroup.co.uk/downloads/brochures/ecosand.pdf (accessed January 22, 2018)

Day Group Ltd (2011) Glass into Aggregate from: http://www.daygroup.co.uk/downloads/brochures/glass_recycling.pdf (accessed January 22, 2018)

Doudart de la Grée GCH (2012). Physical-chemical upgrading and use of bio energy fly ashes as building material in the concrete industry. MSc Dissertation, Eindhoven Univ. of Technology, Eindhoven, Netherlands.

Doudart de la Grée GCH, Yu QL \& Brouwers HJH (2018) Upgrading and Evaluation of Waste Paper Sludge Ash in Eco-Lightweight Cement Composites Journal of Materials in Civil Engineering 30 (3) DOI: 10.1061/(ASCE)MT.19435533.0002186

European Commission (EC) (2000) Directive 2000/76/EC: Incineration of waste. European Commission. 
Fava G, Ruello ML \& Corinaldesi V (2011) Paper mill sludge ash as supplementary cementitious material. Journal of Materials in Civil Engineering 23: $772-776$.

Florea MVA (2016) Environmental interactions of cement-based products. In: Schmidt W. \& Msinjili N. S (Eds.): Advances in Cement and Concrete Technology in Africa: $2^{\text {nd }}$ International Conference, 27-29 January 2016, pp. 3146, Dar es Salaam, Tanzania s.I.: BAM Federal Institute for Materials Research and Testing.

Ishimoto H, Origuchi T \& Yasuda M (2000) Use of papermaking sludge as new material. Journal of Materials in Civil Engineering 12: 310-313.

Ismail ZZ Al-Hashmi EA (2009) Recycling of waste glass as a partial replacement for fine aggregate in concrete. Waste Management 29(2): 655659.

Kadu A \& Gajghate VK (2016) Using Hypo Sludge Ash in Design Mix Concrete International Journal for Scientific Research \& Development (IJSRD) 4 (3): 6366

Limbachiya MC (2009) Bulk engineering and durability properties of washed glass sand concrete. Construction and Building Materials 23: 1078-1083

Mavroulidou M Awoliyi S (2017) A study on low energy demand materials used in glasscrete to counteract alkali-silica reactions, $15^{\text {th }}$ International Conference 
on Environmental Science and Technology CEST2017, Rhodes, Greece, 31 August to 2 September 2017 From: https://cest.gnest.org/taxonomy/term/449 (accessed January 22, 2018)

Mavroulidou M, Boulouki G \& Unsworth C (2013) Incorporating waste paper sludge as partial cement replacement in concrete. $13^{\text {th }}$ International Conference on Environmental Science \& Technology, CEST2013, Athens, Greece, 5-7

September 2013. ISSN 1106-5516, from

http://www.gnest.org/proceedings/cest2013/public html/papers/0336.pdf (accessed January 22, 2018)

Mavroulidou M, Morrison T, Unsworth C \& Gunn MJ (2015) Properties of concrete made of multicomponent mixes of low-energy demanding binders. Construction and Building Materials 101: 1122-1141

Mavroulidou M, Murawski M, Hussein AH (2011) Properties of concrete with low energy demand binders, $11^{\text {th }}$ International Conference on Environmental Science and Technology, Rhodes, Greece, 4-8 September 2011, pp A1218A1225; ISSN 1106-5516. ISBN 978-960-7475-49-7

Mozaffari E, Kinuthia JM, Bai J \& Wild S (2009) An investigation into the strength development of Wastepaper Sludge Ash blended with Ground Granulated Blastfurnace Slag. Cement and Concrete Research 39: 942-949 
Mozaffari E, O'Farrell M, Kinuthia JM \& Wild S (2006) Improving strength development of wastepaper sludge ash by wet-milling. Cement and Concrete Composites 28: 144-152

Neville, A.M. (1995). Properties of concrete $\left(4^{\text {th }}\right.$ Ed), Harlow: Longman.

Rajgor MB \& Pitroda J (2013) A Study on Paper Industry Waste: Opportunities for Development of Low Cost Concrete in Indian Context. International Journal of Scientific Research 2(2): 90-92

Roy DM, Arjunan P \& Silsbee MR (2001) Effect of silica fume, metakaolin, and low-calcium fly ash on chemical resistance of concrete, Cement and Concrete Research 31: 1809-1813

Shafaatian S, Akhavan A, Maraghechi H \& Rajabipour F (2013) How does fly ash mitigate alkali-silica reaction (ASR) in accelerated mortar bar test (ASTM C 1567)? Cement and Concrete Composites 37(1): 143 - 153.

Spathi, C. (2016). Novel applications for paper sludge ash, PhD thesis, Imperial College, London

Wong HS, Barakat R, Alhilali A, Saleh M \& Cheeseman CR (2015) Hydrophobic concrete using waste paper sludge ash. Cement and Concrete Research 70: 9 -20 .

Wright JR, Cartwright C, Fura D, \& Rajabipour F (2014) Fresh and Hardened Properties of Concrete Incorporating Recycled Glass as 100\% Sand 


\begin{abstract}
Replacement. Journal of Materials in Civil Engineering 26(10) 04014073, doi: 10.1061/(ASCE)MT.1943-5533.0000979 Yousuf, Adil BA \& Rafique A (2014) Sustainable use of paper wastes (hypo sludge) in concrete mix design. In: First International Conference on Emerging Trends in Engineering, Management and Sciences December 28-30, 2014 (ICETEMS-2014) Peshawar, Pakistan
\end{abstract}




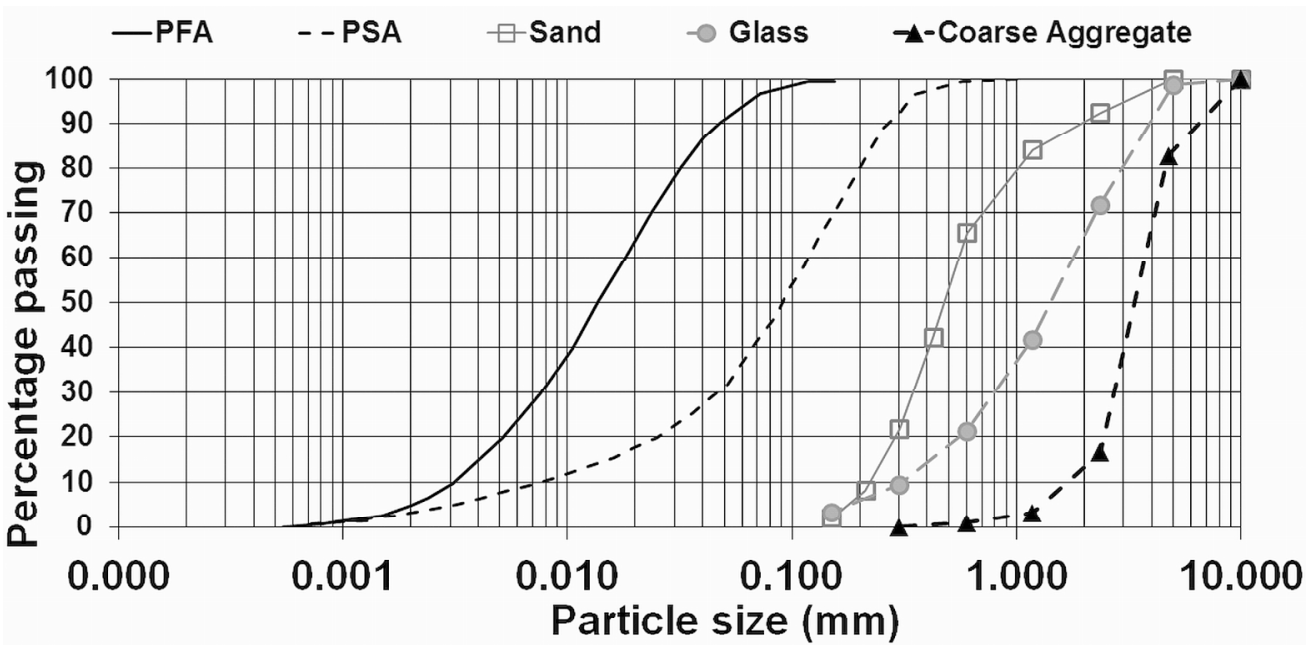

Figure 1 Particle size distribution (PSD) of aggregates and PFA/PSA binders $508 \times 249 \mathrm{~mm}(96 \times 96$ DPI $)$ 

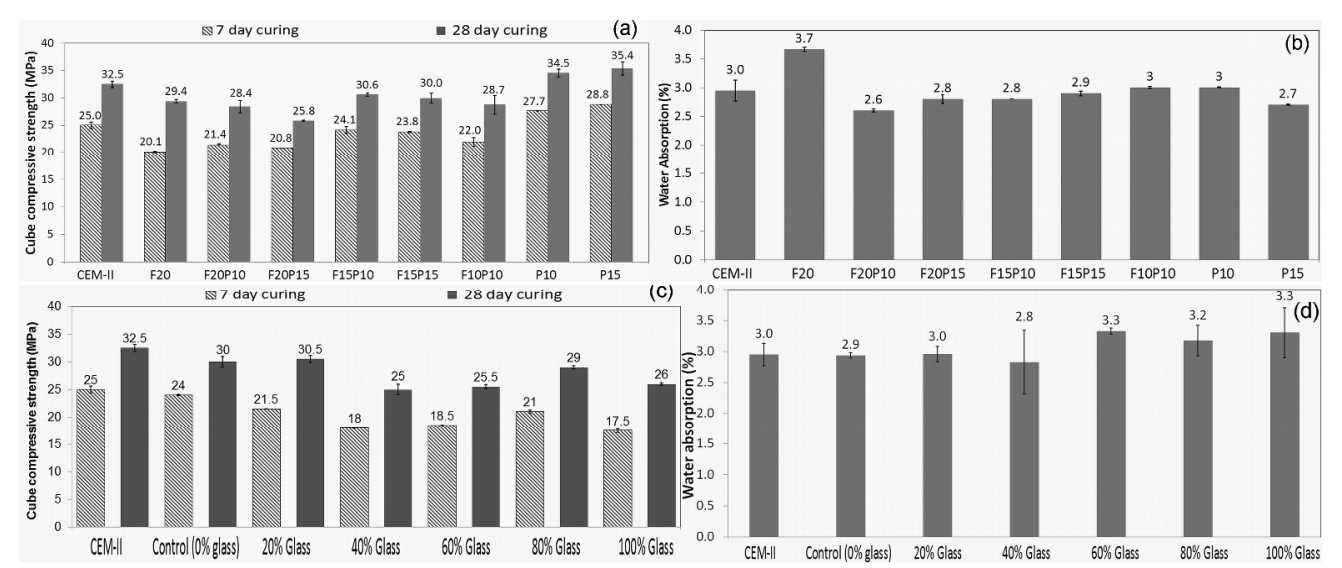

Figure 2 Hardened concrete properties: (a) Cube compressive strength of preliminary mixes; (b) Water absorption of preliminary mixes; (c) Cube compressive strength of WGA mixes; (d) Water absorption of WGA mixes

$1047 \times 437 \mathrm{~mm}(96 \times 96 \mathrm{DPI})$ 